\title{
La creatividad en el gobierno de nuestras vidas: reflexiones sobre la maternidad
}

\author{
LAURA ADRIÁN LARA**
}

Artículo recibido: $1^{\circ}$ de octubre de 2014

Artículo aprobado: 20 de febrero de 2015

Doi: dx.doi.org/10.12804/desafios27.2.2015.01

Para citar este artículo: Adrián Lara, L. (2015). La creatividad en el gobierno de nuestras vidas: reflexiones sobre la maternidad. Desafíos, 27(II), 21-52. Doi: dx.doi.org/10.12804/ desafios27.2.2015.01

\section{Resumen}

Algobernarse democráticamente, los ciudadanos despliegan su capacidadpara afrontar la realidad de forma creativa. La contingencia nos obliga día a día a pararnos a pensar y a cultivar nuestro buen juicio. En el pensamiento de Hannah Arendt, la acción, que es la esencia de la politica, se asocia con la natalidad. La acción da lugar a un nuevo comienzo y revela a cada ciudadano como un ser único. Sin embargo, la acción queda separada de la labor, de las tareas propias del oikos. Por otra parte, el protagonismo que se le da al logos en la polis nos hace olvidar la importancia de los silencios, como los silencios infantiles, y nos resta capacidad para comprenderlos y atenderlos adecuadamente. En este artículo, nos proponemos meditar sobre la mater-

\footnotetext{
* Una versión previa de este trabajo fue presentada en el I Encuentro Internacional sobre el Mundo Interno y la Política (Universidad Austral de Chile, Valdivia, 23-24 de septiembre de 2014). El origen de estas reflexiones está en los seminarios de investigación sobre psicoanálisis y sobre pensamiento griego que organizó el profesor Javier Roiz durante 2012 y 2013. Me gustaría agradecer al profesor Roiz y a mis colegas los diálogos que compartimos en estas sesiones. También agradezco al profesor Daniel Blanch su ayuda en la edición del manuscrito.

** Doctora en Ciencias Políticas por la Universidad Complutense de Madrid. Colaboradora honorífica del Departamento de Ciencia Política y de la Administración II, Facultad de Ciencias Políticas y Sociología, Universidad Complutense de Madrid. Miembro colaborador de la FLACSO-España. Correo electrónico: ladrianlara@gmail.com
} 
nidady su relación con nuestra creatividad en el gobierno de nuestras vidas. Elpapel de los maternos muestra nuestra capacidad para relacionarnos con otro ser bumano desde el mundo interno, a través de una relación letárgica en la que no media un lenguaje articulado. También nos alerta sobre los peligros de la omnipotencia que va ligada a ella y nos recuerda nuestro origen de absoluta dependencia.

Palabras clave: maternos, silencio, omnipotencia, letargia, falso self.

\title{
Creativity in Governing our Lives: Reflections on Maternity
}

\begin{abstract}
In governing themselves democratically, citizens display their capacity to address reality in a creative fashion. On a daily basis contingency forces us to stop and think, and to cultivate good judgement. In Hannah Arendt's thought action, which is the essence of politics, is associated with natality. Action gives rise to a new beginning and reveals that each citizen is unique. Yet action is to be distinguished from labor, from the tasks of the oikeos. Moreover, the central role of the logos in the polis leads us to forget the significance of the silences, such as the silence of infants, and detracts from our capacity to understand and pay attention to them adequately. In this article we will meditate on maternity and its relationship to our own creativity in governing our lives. The role of maternal individuals shows our capacity to relate to another buman being through our internal world, by means of a lethargic relationship that is not mediated by an articulated language. It also alerts us to the dangers of the omnipotence to which it is linked and reminds us of our origins as fully dependent beings.
\end{abstract} Keywords: maternal individuals, omnipotence, lethargy, silence, false self.

\section{A criatividade no governo de nossas vidas: reflexões sobre a maternidade}

\begin{abstract}
Resumo
Ao governar-se democraticamente, os cidadãos desenvolvem sua capacidade para afrontar a realidade de forma criativa. A contingência nos obriga-nos diariamente a para a pensar e a cultivar nosso bom juízo. No pensamento de Hanna Arendt, a ação, que é a essência da política, associa-se com a natalidade. A ação condur a
\end{abstract}


um novo começo e revela a cada cidadão como um ser único. No entanto, a ação fica separada do trabalho, das tarefas próprios do oikos. Por outra parte, o protagonismo que lhe é dado ao logos na polis faz-nos esquecer a importância dos silêncios, como os silêncios infantis, e resta-nos capacidade para compreendê-los e atendê-los adequadamente. Neste artigo, propomo-nos meditar sobre a maternidade e sua relação com nossa criatividade no governo de nossas vidas. O papel dos maternos mostra nossa capacidade para nos relacionar com outro ser bumano desde o mundo interno, através de uma relação letárgica na que não media uma linguagem articulada. Também nos alerta sobre os perigos da omnipotência que vai ligada a ela e recorda-nos nossa origem de absoluta dependência.

Palavras-chave: maternos, silêncio, omnipotência, letargia, falso self.

"[S]er alguien comporta la renuncia a serlo todo". Veguetti-Finzi (1996, p. 153)

El teatro, escribió Hannah Arendt (1906-1975), es el "arte político por excelencia", porque "solo en él se transpone en arte la esfera política de la vida humana. Por el mismo motivo, es el único arte cuyo solo tema es el hombre en su relación con los demás" (Arendt, 2005, p. 216).

Quizá por ello sea una fuente tan rica para meditar sobre el tema que nos proponemos en este trabajo: la relación entre la creatividad, la maternidad y el gobierno de nuestras vidas.

\section{La vida sin palabras}

En ocasiones, los niños aparecen como personajes mudos, cuya presencia resulta casi espectral. Es el caso de Eurísaces, el hijo de Áyax, personaje que protagoniza y da nombre a una de las tragedias de Sófocles (495 a. E. C.-406 a. E. C.).

Eurísaces entra en escena de la mano de un esclavo. Su padre ha reclamado a su esposa, Tecmesa, que se lo traigan (Sófocles, 2011a, p. 58). El hecho de que el niño no diga nada durante su presencia en el escenario, a pesar de tener un papel relevante en la acción, puede que 
nos pase desapercibido en la primera lectura. Al principio pensamos que quizá sea un niño pequeño, todavía in-fantil, en sentido literal. Es decir que todavía no está capacitado para hablar. ${ }^{1}$ Cuando caemos en la cuenta de que tal vez sí tiene suficiente edad como para expresarse con palabras, ${ }^{2}$ aunque estas fueran rudimentarias, su mutismo aparece como un agujero. Intuimos que el silencio es su forma de expresión y que los espectadores de la época lo aceptarían como algo natural. Es un silencio que no se traduce en nada más. No dice nada y da la impresión de que nada deberíamos esperar de él. Sobre el escenario, puede que la figura de Eurísaces adquiriera cierto relieve para los espectadores, dado que podrían verlo. Los lectores de la obra, sin embargo, tenemos que figurarnos su presencia de oído. La intuimos gracias a que los demás personajes se dirigen a él y lo manipulan: el esclavo lo trae "de la mano", su padre lo "toma en brazos" y le habla, después se lo "entrega" a su esposa, que lo saca de la escena y lo vuelve a introducir en ella (Sófocles, 2011a, pp. 58-60, 86). La figura del niño se presenta como si se tratara de un recipiente hueco y opaco. Lo captamos como una ausencia.

En nuestra tradición política, en gran parte heredera de Grecia, tener la palabra se asocia a poseer entidad política y contar con el reconocimiento de los demás ciudadanos. Ser ciudadano implica el derecho a decir y a ser escuchado por los demás, otorgándose prestigio mutuo. En esto consiste la isegoría (Arendt, 2006, p. 70; Roiz, 2003, pp. 171-176). Este planteamiento excluye a los que por su corta edad o falta de cualidades no son capaces de expresarse adecuadamente con palabras. Podemos pensar en aquellos que son incapaces de decir; pero también nos preocupan los de alrededor, que no sabemos

\footnotetext{
1 Como explica Donald W. Winnicott (1896-1971), infantil hace referencia a la incapacidad para hablar. 'Actually the word infant implies 'not talking' (infans), and it is not un-useful to think of infancy as the phase prior to word presentation and the use of word symbol" (Winnicott, 1986, p. 236). Ver además Roiz (2003, pp. 156-157, 322-323).

2 En la escena final, Teucro le pide a Eurísaces que colabore en levantar el cuerpo muerto de su padre: "Hijo, tú levanta conmigo estos costados en la medida de tus fuerzas, cogiendo el cuerpo de tu padre con cariño, pues sus venas calientes están todavía exhalando el negro humor de su sangre" (Sófocles, 2011a, p. 86). Si el niño tenía capacidad para hacer tal cosa, suponemos que debía tener al menos 5 o 6 años.
} 
o no podemos escucharles, aunque cabría preguntarse de antemano si acaso nos lo llegamos a proponer seriamente.

La isegoría constituye un fermento muy valioso para que broten relaciones democráticas. Sin embargo, si no se profundiza en su significado retórico, ${ }^{3}$ se corre el riesgo de aceptar que tener la palabra equivale a tener acceso alpoder. Cuanta mayor sea nuestra capacidad para hablar el lenguaje adulto, mayor poder seremos capaces de adquirir. De manera análoga, quien no pueda expresarse de este modo quedará relegado a la impotencia y carecerá de un gobierno autónomo. Aceptado este orden de cosas, quitarle la palabra a alguien equivale a degradarle y tratar de hacerle invisible. Es lo que pretende Telémaco al hablar de este modo a su madre, Penélope, y con ella a todas las mujeres: "[V]ete dentro de la casa y ocúpate de tus labores propias, del telar y de la rueca, y ordena a las criadas que se apliquen al trabajo. El relato está al cuidado de los hombres, y sobre todo al mío. Mío es, pues, el gobierno de la casa” (Homero, 2011, I, 356-359, p. 54).

En un niño, como Eurísaces, se admite que aparezca en los escenarios de la vida ${ }^{4}$ como una figura que no habla. Se tolera esta situación porque se tiene la esperanza de que crecerá y se expresará por sí mismo cuando llegue el momento apropiado. Pero ¿qué ocurre si un adulto no tiene voz propia? En ese caso, el silencio se nos hace más inquietante. Podría interpretarse que la persona es un ignorante, un inmaduro o, en el peor de los casos, un sometido o un dimisionario. Alguien sin coraje para mostrar su voz y hacerse cargo de su entidad como ciudadano, o alguien que ha renunciado a su ciudadanía, como hace Esaú con su derecho de primogenitura (Wolin, 1986, pp. 179-182). En esos casos, puede que los más entusiastas se ofrezcan a prestarles su voz con la esperanza de que ese gesto termine por

\footnotetext{
3 Para la retórica democrática, el punto de partida no son las palabras, sino el silencio que ofrece el auditorio y que permite que alguien pueda decir algo a los demás (Roiz, 2013, pp. 81-82, 249).

4 Sobre el significado de los escenarios en la vida y el gobierno de las personas, ver Roiz (2013, pp. 247 y ss.).
} 
envalentonarlos y logren hablar por sí mismos. Pero quizá todas estas sean interpretaciones y reacciones demasiado precipitadas.

El uso de la palabra está muy asociado con la adquisición de visibilidad pública, con mostrarnos ante los demás y, a la vez, revelar fragmentos de la realidad que de otro modo permanecerían enterrados en la oscuridad. Estamos acostumbrados a hablar de la necesidad de dar voz a los oprimidos, o de dar visibilidad a problemas que la sociedad ignora o trata de ocultar — sea con complicidad o por miedo-. La palabra y la presencia visual se nos ofrecen como dos fenómenos parejos que contribuyen a que nuestras relaciones y nuestra comprensión de la realidad sean accesibles al control público. Confiamos con optimismo en que el lenguaje nos permitirá identificar los problemas y hacer que penetre la lógica en ellos para analizarlos y resolverlos. Sin embargo, no es difícil darse cuenta de que fuera del circuito democrático de las demandas que han logrado sacar la cabeza a flote y expresarse, e incluso con suerte ser escuchadas y atendidas por alguien, late subterránea una maraña de voces calladas, amorfa, sin límites conocidos, sin predicados y sin sujetos. Cuando nos topamos con figuras que solo emiten gemidos o frases inconexas, como ocurre en el teatro de Tadeusz Kantor (1915-1990), aparece una sensación angustiosa de desconcierto y perplejidad, de no saber cómo interpretar lo que sucede (Kantor, 2008). No obstante, hay algo en ese mundo sin palabras, mudo pero muy expresivo, que nos impacta y conmueve profundamente.

En un espacio público diáfano y poblado de presencias, el enigma del silencio es asociado con ocultación. Cuando quedamos en silencio, nos ocultamos ante los demás. Si mediante la acción y la palabra revelamos nuestro verdadero ser, explica Arendt, la ausencia de palabras o de acción impide que los demás nos reconozcan: "El descubrimiento de 'quién' en contradicción al 'qué' es alguien — sus cualidades, dotes, talento y defectos que exhibe u oculta—, está implícito en todo lo que ese alguien dice y hace. Sólo puede ocultarse en completo silencio y perfecta pasividad" (Arendt, 2005, pp. 208-209).

Mejor identificados, más reconocibles, con el lenguaje nos sentimos también más protegidos ante el mundo. Cuando ya se saben utilizar, 
las palabras pueden servir como una herramienta adulta para hacernos impermeables ante la dureza del entorno. Así se expresa Bernard, uno de los personajes de la novela de Virginia Woolf (1883-1941) titulada Las olas: "Todos saben que ingreso en la escuela superior, que por primera vez voy a la escuela superior [...] Debo esforzarme en no llorar. Debo mirarlos a todos con indiferencia [...] Debo construir frases y frases para interponer algo duro entre yo y la mirada de las criadas, la mirada de los relojes, los rostros observantes, los rostros indiferentes, o de lo contrario lloraré" (Woolf, 2012a, p. 25). ${ }^{5}$

Saber emplear el lenguaje con cierta sofisticación nos ayuda a tomar conciencia de nosotros mismos, nos ayuda a pensar y a trasladar nuestro pensamiento a los demás. Naturalmente no podemos esperar que las palabras digan lo que queremos decir de forma plenamente satisfactoria. Para Henri Bergson (1859-1941), tratar de expresar con palabras nuestros pensamientos es una tarea parecida al intento de un niño por atrapar el humo con las manos (Arendt, 2002, p. 145). A nuestra posible incapacidad se suma el hecho de que, si se dan las condiciones apropiadas, habrá otras personas que nos escucharán e interpretarán lo que digamos libremente, aportando sus fantasías, sus afectos y su inteligencia.

A pesar de todos estos vericuetos, al lenguaje le atribuimos unas cualidades fascinantes para conectarnos con sutileza y hondura con los demás y, gracias a ello, sentirnos más acompañados en nuestro dolor ${ }^{6}$ o en nuestra felicidad. Confiamos en que el lenguaje nos servirá como un instrumento pacífico para gobernarnos y también para aprender a gobernarnos. Es una herramienta básica de la terapia psicoanalítica (Winnicott, 1987, p. 92) como lo es en la docencia, en la

\footnotetext{
5 Agradezco a Pedro Mendoza Lamuño que me diera a conocer este valioso escrito de Virginia Woolf y sus conexiones con el 'mundo interno'. Para profundizar en este tema, es muy recomendable la selección de textos presentada en Woolf (2014).

6 Arendt toma como cita de entradilla para el capítulo V de La condición humana esta reflexión de Isak Dinesen que alude a la importancia de dar sentido a los hechos mediante los relatos: "Todas las penas pueden soportarse si las ponemos en una historia o contamos una historia sobre ellas" (Arendt, 2005, p. 205).
} 
relación entre maestro y discípulo. ${ }^{7}$ En una democracia, se considera el sustituto avanzado y benigno de relaciones más primitivas basadas en la violencia y la obediencia ciega a órdenes que no son explicadas con razones. ${ }^{8}$

Sus virtudes son notables, pero quizá no debiéramos dejarnos encandilar por las palabras y esperar de ellas demasiado. Puede ocurrir que nos concentremos tanto en ellas que no nos demos cuenta de que en ocasiones nos tapamos los oídos, no para protegernos del canto seductor de las sirenas, como creía hacer Odiseo, sino para evitar escuchar unos silencios que nos asustarían aún más. ${ }^{9}$

Unos silencios que podrían significar soledad, abandono, incluso presagios de desamparo. Ante ellos — medita la nodriza que acompaña a Medea- es difícil encontrar cantos y músicas que nos reconforten: " $[\mathrm{M}]$ ortal alguno inventó el modo de poner fin, con música y canciones de tonos variados, a las tristezas del odio que engendran destrucciones y muertes, ruinas de las casas. Sí que sería provechoso a los hombres con cantos y danzas curar esas desdichas" (Eurípides, 1990a, pp. 53-54).

Las palabras revelan a duras penas lo que pretenden expresar. En la Biblia, se nos advierte de ello, a su modo, cuando se separa en dos figuras quien recibe la revelación de aquel que tenía las cualidades para comunicarla. Como Moisés era "torpe de palabra”, Yahvé encomendó a su hermano Aarón ser su profeta ante el faraón (Éxodo 6: 30; 7: 1-2). La separación que realiza Arendt entre el protagonista de la acción y el narrador, que puede dar cuenta de ella de una forma más

\footnotetext{
7 A este respecto es muy valioso considerar la cercanía entre la tradición de enseñanza de uno en uno cultivada por Moisés Maimónides (1138-1204) y el psicoanálisis de Sigmund Freud (1856-1939) (Roiz, 2008, pp. 36-38, 47-49).

8 Basta recordar el pasaje de la Política de Aristóteles (384 a. E. C.-322 a. E. C.) en el que se ensalza el valor del logos como una cualidad genuinamente humana que nos sirve para "manifestar lo conveniente y lo perjudicial, así como lo justo y lo injusto" (Pol., 1253a 11 ss.).

$9 \quad$ Ver la interpretación que hace Franz Kafka (1883-1924) de este pasaje de la Odisea (Kafka, 2005, pp. 177-178).
} 
cabal que aquel (Arendt, 2005, pp. 209, 212-213, 219), también puede comprenderse como una protección democrática; una advertencia para no sobrestimar nuestras capacidades como autores autónomos de nuestra vida (Arendt, 2005, p. 213).

Pero sus limitaciones no quedan ahí. En muchas ocasiones, las palabras cumplen la función de ocultar, de "velar intenciones" en lugar de "descubrir realidades" (Arendt, 2005, p. 226). Tenemos un ejemplo del dolor que estos manejos producen en el diálogo entre Medea y Jasón recreado por Eurípides en la tragedia titulada Medea.

Ante una situación que a Medea la desborda, Jasón opta por comportarse como un "piloto" responsable y locuaz, ${ }^{10}$ algo que a Medea la desquicia aún más. Jasón se propone "mostrarle" todos los beneficios que le ha proporcionado a Medea su matrimonio con él, para que entienda que él no está en deuda con ella, y que su nueva boda es buena para ambos. A continuación, empieza la reconstrucción dialéctica de la situación.

Le explica que, en primer lugar, si ella le ayudó a él fue por amor; y, en segundo lugar, que, si bien es cierto que él se benefició de su ayuda, fue mayor el beneficio que ella obtuvo a cambio. Con su unión, Medea ha pasado a vivir en "suelo griego" y los griegos han llegado a conocer su ciencia, lo que le ha procurado "gloria" y "fama" (Eurípides, 1990a, pp. 64-65).

El origen de la discordia es que Jasón ha abandonado a Medea y, a sus espaldas, se ha casado con la joven princesa Creúsa, hija de Creonte, el rey de Corinto. La situación se ha agravado por la irreverencia de Medea y esta va a ser expulsada de la ciudad junto a sus hijos. Jasón le explica que no le ha movido el deseo de cambiar de esposa, ni

\footnotetext{
10 "Debo mostrarme, a lo que veo, elocuente y cual hábil piloto de una nave recoger las velas y capear, mujer, la furia desmedida de tu lengua" (Eurípides, 1990a, p. 64). Es interesante notar que Eteocles adopta un rol semejante al dirigirse a los tebanos: "Palabras muy acertadas ha de decir, ciudadanos de Tebas, quien en la popa del país, la maniobra dirige, timón en mano, sin permitir que sus párpados se cierren para dormirse" (Esquilo, 2005, p. 103).
} 
deseaba a una mujer más joven ni estaba a disgusto con Medea. Era una cuestión mucho más práctica. Se trataba solamente de aprovechar la mejor oportunidad que se le había presentado — nada menos que desposar a la hija del rey- para asegurarse un futuro "sin privaciones", él que es un "exiliado” (Eurípides, 1990a, p. 65). A Jasón le parece que este recuento de ventajas debería llevar a Medea a comprender y aceptar la nueva situación. Considera que al actuar así él ha "sido sabio y prudente" y ha demostrado mirar por los intereses de los hijos que tienen en común (Eurípides, 1990a, p. 65).

En este diálogo trascendental, Jasón insiste en pedirle a Medea que mantenga la "calma" (Eurípides, 1990a, p. 65). A su antigua esposa se le hace insoportable que se trate de tapar el daño que se le está haciendo con esta falsa prudencia. El coro se pone de su lado: "Bien has adornado, Jasón, tus palabras. Sin embargo, a mí —y puede que ello te decepcione - me parece que, al traicionar a tu esposa, no obras con justicia” (Eurípides, 1990a, pp. 65-66).

Medea siente que los razonamientos de Jasón ocultan las razones verdaderas de los hechos y tratan de amagar su dolor sin hacer el esfuerzo de comprenderla, convirtiendo su queja en algo fuera de lugar e incomprensible. ${ }^{11}$ Por ello, se expresa de este modo: "Para mí el malvado de natural elocuente es merecedor del máximo castigo. Confiado en cubrir bien con su lengua sus actos de injusticia, osa cometer cualquier bajeza" (Eurípides, 1990a, p. 66).

Medea utiliza las palabras con malicia y se vale del engaño tanto al hablarle a Creonte, para pedirle que le permita quedarse un día más en la ciudad, como al dirigirse a Jasón, con la intención de hacerle creer que ha cambiado de parecer y apoya su plan (Eurípides, 1990a, pp. 58-59, 73, 77-80). Quizá la diferencia es que ella no se oculta a sí misma la perversidad de su propósito (Eurípides, 1990a, p. 84).

\footnotetext{
11 Jasón le llega a decir: “¿Está, acaso, mi plan mal discurrido? Ni tú misma podrías negarlo si no te irritara el lecho abandonado. Vosotras las mujeres habéis llegado a un punto en que creéis tenerlo todo si tenéis el gozo asegurado; mas, si algo viene a turbarlo, consideráis la cosa más odiosa lo que precisamente es lo más provechoso" (Eurípides, 1990a, p. 65).
} 
Ella es el único personaje de quien conocemos sus reflexiones y sus sentimientos más allá de lo que muestra hacia los demás. Duda, llora, se conmueve ante la situación, sus palabras y sus reacciones se contradicen (Eurípides, 1990a, pp. 73, 78-79, 81-84, 89-90). No hay, sin embargo, a pesar de estos quebrantos, oportunidad para que brote el pensamiento y el buen juicio. Su corazón está envenenado por el odio y ya "solo a sí se mira", como reconoce con tristeza e impotencia la nodriza (Eurípides, 1990a, p. 50).

La ocultación puede ser hacia los demás o, más inquietante aún, hacia uno mismo y sin que el "piloto" siquiera se dé cuenta de ello. Las palabras pueden caer con facilidad en manos de nuestro falso self y desligarse de una relación veraz con la realidad. Esta situación es si cabe aún más lesiva para la persona. A este respecto Winnicott señala que el falso self del paciente puede cooperar con el terapeuta "indefinidamente": "The patient's False Self can collaborate indefinitely with the analyst in the analysis of defences, being so to speak on the analyst's side in the game" (Winnicott, 1965, p. 152).

Debido a ello, el terapeuta puede tardar un tiempo en darse cuenta de que no se está comunicando con el verdadero self de su paciente.

En ese caso, el lenguaje puede llegar a ser un cómplice de nuestras defensas y favorecer una relación conservadora y desleal con la realidad. Como observa Winnicott, esto es algo que resulta un obstáculo de primer orden para que se despliegue la "originalidad creativa" del individuo. Su carencia será un indicio para reconocer al falso self: "TThe False Self, however well set up, lacks something, and that something is the essential central element of creative originality" (Winnicott, 1965, p. 152).

En términos más generales, Rodríguez Piedrabuena expresa de este modo cómo el lenguaje resulta engañoso y obtura la creatividad: "[E]l ordenado, detallista y locuaz prefrontal izquierdo no se activa ante la novedad; éste [...] se encarga de engañar y de inventarse el relleno para las lagunas cognitivas racionalizando, hablando $[\ldots]$ al hablar ocultamos y lo emocional no puede comunicarse con palabras" (Rodríguez Piedrabuena, 2002, p. 60). 
Arendt asocia de una forma muy alentadora la política con nuestra creatividad. Actuar significa para ella emprender un nuevo comienzo cuyos resultados son impredecibles en el sentido más genuino y liberador del término (Arendt, 2005, pp. 206-207). Implica embarcarnos en una aventura sin tener garantías de llegar a un puerto seguro, como el que promete Egeo (Eurípides, 1990a, p. 73). Significa aceptar el riesgo de la incertidumbre. Es decir, asumir que podemos salirnos de los pautajes y de los rituales piadosos ${ }^{12}$ sin que eso tenga que significar sucumbir al caos o la violencia.

Arendt nos muestra que nuestras palabras y nuestra capacidad para actuar nos dan entrada en el mundo que compartimos. Es una oportunidad muy transformadora para el ciudadano y para la ciudad que permite recrear nuestras identidades sin necesidad de definirlas (Arendt, 2005, pp. 208-211). Nos da la oportunidad de mostramos como seres únicos más allá de los aspectos heredados o determinados por la naturaleza. Nos da la oportunidad también de que los otros entren en nuestra vida y nosotros entremos en la suya. Reconociendo la trascendencia que este paso tiene en nuestras vidas, Arendt lo caracteriza como un "segundo nacimiento": "Con palabra y acto nos insertamos en el mundo humano, y esta inserción es como un segundo nacimiento, en el que confirmamos y asumimos el hecho desnudo de nuestra original apariencia física. A dicha inserción no nos obliga la necesidad, como lo hace la labor, ni nos impulsa la utilidad, como es el caso del trabajo" (Arendt, 2005, p. 206).

En nuestro segundo nacimiento, la mediación del lenguaje parece esencial. Sin embargo, no hay que olvidar que nuestros primeros contactos con el mundo se basan en una relación preverbal. ${ }^{13}$ Esta relación se da entre el in-fante y la persona (o personas) encargadas de su cuidado. En ella

\footnotetext{
12 Tenemos que considerar que la piedad es una actitud muy presente en la mentalidad griega que refleja, por ejemplo, Sófocles en Antígona: "Si entrelaza las normas de la tierra / y la justicia de los dioses permaneciendo fiel al juramento prestado / ¡he ahí un ciudadano de primera!" (Sófocles, 2011b, p. 160).

$13 \mathrm{Al}$ adentrarse en estos territorios, Winnicott advierte: "I'm taking you to a place where verbalization has no meaning" (Winnicott, 1987, p. 91).
} 
no hay mediación de palabras, aunque participe al menos una persona adulta y sus efectos vayan a perdurar en la vida adulta del bebé.

¿Esta relación podrá decirnos algo acerca de los silencios que tendremos que aprender a escuchar y atender en nuestras vidas adultas?

\section{Relación letárgica}

El psicoanálisis nos ofrece una visión muy valiosa de los primeros momentos de la vida de cualquier ser humano sobre la que merece la pena detenerse. Lo haremos de la mano de Donald W. Winnicott y de Nancy Chodorow.

Winnicott señala que el del bebé es un mundo muy pequeño pero en él suceden muchas cosas y de alcance muy profundo. Además es una experiencia, la primera experiencia (Winnicott, 1987, p. 95), que nos dejará marcados de por vida.

Nuestra vida al nacer está caracterizada por una dependencia absoluta que irá transformándose paulatinamente en independencia (Winnicott, 1987, pp. 83, 88; 1986, p. 242). Durante los primeros meses, el bebé es absolutamente dependiente. Este hecho nos obliga a fijarnos en la persona encargada de atender esa dependencia y en la relación que se establece entre ellos.

La madre ${ }^{14}$ y el bebé forman una unidad. Para el bebé, no hay una separación entre ellos. Incapaz de reconocer objetos externos a sí

14 Conviene advertir que nos referimos a la madre, pero no tiene por qué ser la madre biológica ni necesariamente una mujer, aunque quizás estas sean las situaciones más frecuentes. Con el término nos referimos a la persona o personas encargadas de proveer un cuidado maternal. Roiz se refiere a estas personas como los “maternos” (Roiz, 1996, p. 154), quizás un término más adecuado para ello y que evita utilizar un concepto excluyente. Por otra parte, me parece muy valioso el hecho de que Chodorow termine su ensayo con una propuesta para que el padre también forme parte de esa labor maternal. De ese modo, lo masculino no quedaría disociado del cuidado maternal y además este sería ofrecido en plural, por más de una persona. Ello permitiría disolver algunos problemas derivados de que se ocupen de los cuidados maternales solo las mujeres (Chodorow, 1984, pp. 308-319). 
mismo, para el bebé la madre es también él mismo. No diríamos que no hay fronteras entre ellos porque estén fundidos; desde el punto de vista del bebé, en realidad no son dos cosas distintas que haga falta fundir: "El bebé, al nacer, no sólo es completamente dependiente, sino que no es capaz de diferenciarse cognitivamente de su medio ambiente. No diferencia entre sujeto/selfy objeto/otro. Esto significa que no diferencia entre la gratificación y sus necesidades y deseos. El bebé se experimenta como inmerso sin solución de continuidad en el mundo en general y en su madre o en los encargados de cuidarlo en particular" (Chodorow, 1984, p. 98).

La supervivencia física y psicológica del bebé depende de que los maternos sepan y estén dispuestos a hacerse cargo de esta situación tan especial. Su papel es esencial no solo para lograr el bienestar y el confort del bebé. No se trata (solo) de que el bebé viva mejor. La trascendencia de esta cuestión es que, si los maternos dimiten de su tarea, pondrían en riesgo la existencia del bebé. El bebé no puede existir sin ellos. Sin el sostén continuado que los maternos le proporcionan, el bebé no existiría, no sería.

Para expresar esta situación, Winnicott utiliza una frase que resulta chocante pero que tiene una explicación comprensible. Dice Winnicott: "No existe eso que llamamos un niño" (Winnicott, 1986, p. 235). Con ello quizá quiere llamar la atención sobre un hecho que a él como pediatra y psicoanalista le parece esencial y ha orientado sus investigaciones. No hay un infante sin el cuidado maternal que lo atienda. Pensarlo así sería abstraerlo de la realidad y crear una ficción. "Dondequiera que se encuentre a un niño (an infant), se encuentra cuidado maternal, y sin cuidado maternal no habría un niño [...] el potencial heredado por un niño no puede convertirse en un niño a menos que esté vinculado al cuidado maternal" (Winnicott, 1986, pp. 235, 239).

En resumen, nuestros primeros meses de existencia están marcados por la dependencia absoluta y por la presencia de al menos una figura maternal que ha atendido satisfactoriamente esta dependencia $y$, gracias a ello, nos ha permitido sobrevivir. 
En el pequeño mundo del bebé, son importantes detalles como el tejido de la ropa que roza su piel, los olores que percibe, el calor que le dan los brazos que le acogen. En su mundo no existe el tiempo que marcan los relojes ni el espacio como lo medimos los adultos. El tiempo está marcado por los latidos del corazón de su madre, el ritmo de su respiración o las tensiones de los impulsos (Winnicott, 1987, p. 95). Una separación demasiado larga (unos minutos o unas horas) de todo contacto humano puede desencadenar angustias muy fuertes, que, si se pudieran traducir en palabras, serían algo así como "partirse en pedazos", "caída interminable", "morir y morir y morir", "total desesperanza de que se renueven los contactos". ${ }^{15}$ Una ansiedad difícil de pensarse o imaginarse ("unthinkable anxiety") (Winnicott, 1987, p. 98) y que el bebé no está capacitado para soportar por sí mismo.

Winnicott explica con detalle cómo el primer contacto del bebé con el mundo es a través de los brazos maternos que lo sostienen. En ese pequeño universo, siente el latido del corazón de su madre, su olor, si se sobresalta por algún ruido doméstico como el timbre o el silbido de la tetera (Winnicott, 1987, p. 19). La lactancia también constituye una forma de comunicación esencial. A través de ella, la figura maternal no solo alimenta a su hijo, en el sentido de proporcionarle los nutrientes necesarios para su crecimiento. Además, le comunica su amor en silencio, se lo hace vivir (Winnicott, 1987, p. 98), ${ }^{16}$ y nutre sus sueños con una experiencia muy rica. ${ }^{17}$

Si los maternos ejercen su labor adecuadamente, el bebé recibirá el resultado. Que el cuidado sea verdaderamente un buen cuidado (suficientemente bueno, en términos de Winnicott) es sentido por el bebé

\footnotetext{
15 "[G]oing to pieces", "Falling for ever", "Dying and dying and dying", "Losing all vestige of hope of the renewal of contacts" (Winnicott, 1987, p. 86). Tomo la traducción de la versión española: Winnicott (1990, p. 115). Ver también Winnicott (1987, pp. 98-99).

16 Ver, así mismo, Winnicott $(1987$, p. 61). En otro lugar, Winnicott señala que la madre y el bebé comparten "a song without words" (Winnicott, 1987, p. 79).

17 "A great deal of the baby's waking life at first has to do with feeding. In a way, the baby is gathering stuff for dreaming, although soon there are all the other things that also become gathered in and which can reverberate in the inner reality of the sleeping child, who is of course dreaming" (Winnicott, 1987, p. 29).
} 
y tiene consecuencias reales en su crecimiento. No hay necesidad de palabras mediadoras que expliquen, justifiquen o racionalicen nada. El niño siente cuando le cogen unos brazos que no están capacitados para sostenerle (Winnicott, 1986, pp. 245-246). Es llamativo que el bebé perciba especialmente cuando el cuidado fracasa, mientras que, si el cuidado es satisfactorio, el bebé lo asume sin percatarse de él (Chodorow, 1984, p. 131). "Si se lo satisface, trae consigo un tranquilo bienestar del bebé” (Chodorow, 1984, pp. 102-103).

Es un cuidado de pequeños gestos, cotidiano, constante, de días y noches (Winnicott, 1986, p. 245). A través de él se establece una relación de mundo interno a mundo interno. La figura materna es capaz de atender adecuadamente al bebé porque, sin que medie el lenguaje (que el bebé no sabe utilizar) ni ningún otro signo, es capaz de captar cuáles son sus necesidades y está dispuesta a atenderlas. El materno descubre las necesidades del bebé gracias a que se identifica con él. Puede anticiparse a lo que el bebé necesita y proveerle de ello. Esto incluye atender necesidades básicas, como alimentarle cuando tiene hambre o protegerle los ojos del sol, y también otras más sutiles, como satisfacer su necesidad de escuchar su respiración (Winnicott, 1987, pp. 85-86).

El cuidado maternal satisfactorio requiere un vínculo amoroso. El cuidado del cuerpo del bebé aplicando las rutinas de alimentación e higiene necesarias no basta para que esté sano física y psicológicamente. Lo importante es la calidad de ese cuidado. Eso incluye un contacto físico amoroso. Cuando ese contacto falta, señala Chodorow, el bebé puede enfermar e incluso morir (Chodorow, 1984, pp. 54, 97, 102).

\section{Inteligencia silenciosa ${ }^{18}$}

Los maternos tienen encomendada una tarea trascendental. Sin embargo, señala Winnicott, no necesitan que nadie les enseñe a realizar esta labor. Sabrán ofrecer un cuidado suficientemente bueno de forma

18 Sobre el concepto de 'inteligencia silenciosa', ver Roiz (2013, pp. 16 y ss.). 
espontánea sin necesidad de leer libros especializados. Esto nos da a entender que el conocimiento que requieren los cuidados del bebé para atender su cuerpo y su psique no son conocimientos intelectuales. Winnicott indica que de modo natural la "madre devota" — que es sencillamente aquella que toma el cuidado de su bebé como una tarea de la que está al cargo (Winnicott, 1987, pp. 4-5)— se identifica con su bebé y es capaz de atender sus necesidades.

En este punto, puede chirriar que Winnicott hable de que el buen cuidado se da de un modo natural. Lo natural tiene muchas implicaciones desde el punto de vista de la teoría política. Puede significar predeterminación y llevar implícita la censura a lo antinatural. Además, puede ser frustrante pensar que, por surgir de forma natural, esas capacidades no se puedan enseñar y cultivar.

Dejando estas consideraciones de lado por el momento, lo que nos interesa es que nos da a entender que el vínculo íntimo entre la madre y el bebé, entre el mundo interno de la madre y el mundo interno del bebé, ${ }^{19}$ se alimenta de capacidades de la inteligencia que van más allá de la razón. Son esas capacidades las que están involucradas en el pensamiento y el juicio (Arendt, 2002). La madre, o los maternos, deben comprender y atender a su bebé en cada momento, y cada bebé es distinto (Winnicott, 1986, p. 245). Es una labor pegada a la contingencia, realizada de forma intuitiva y con una base imprescindible de dedicación amorosa. En ello, observa Winnicott, no tiene sentido que intervenga la ciencia con sus prescripciones si esa ciencia es torpe y no alcanza a comprender que el bebé es algo más que "sangre y huesos" (Winnicott, 1987, p. 24). Winnicott se refiere a la medicina, que es el conocimiento más familiar para él y que se ocupa de estos temas. La ciencia política, por el contrario, quizás adolece de una comprensión demasiado espiritualizada y le cuesta acercarse a pensar sin prejuicios en esta "experiencia fronteriza" que representa la infancia (Roiz, 1992, pp. 154-155).

19 En el caso del bebé, lo interno y lo externo serían difíciles de diferenciar hasta que el bebé no comienza a captar su separación del entorno. 
Estas tareas repetidas cada día no son una mera reproducción de la vida. Considerar que son tareas repetitivas que no llevan a ninguna parte quizá sea producto de comprender el cuerpo desde el alma. Si nos detenemos a observar a una madre lactante sosteniendo a su bebé, tal vez seamos capaces de pensar en el cuerpo desde el mundo interno. El cuerpo es protagonista en esa relación letárgica, en la que opera la inteligencia silenciosa que - a diferencia del pensamiento, que también es efímero y no deja rastro, como sí lo hacen los productos del trabajo o la acción (Arendt, 2005, p. 114) — no requiere de palabras para ser transmitida. Los cuidados cotidianos, repetidos día a día, una y otra vez, sin descanso, sin abandonos, dejarán un poso muy profundo en la vida del bebé. Esta experiencia de sentirse querido y no abandonado le dejará huellas que durarán de por vida y le permitirán vivir. Me refiero a vivir en el sentido pleno en que lo expresa Winnicott, como la capacidad para afrontar la realidad de forma creativa (Winnicott, 1971, p. 65; 1987, p. 25). Aunque el cuidado no tenga alcance público y aparentemente no deje rastro, en el mundo interno del infante sí queda registrado (Winnicott, 1987, p. 98). Tanto es así que la madre recupera su experiencia como hija para atender a su bebé (Winnicott, 1987, pp. 6, 85) ${ }^{20}$ Si el cuidado fracasa, sin embargo, puede que esas huellas sean heridas difíciles de sanar.

Vistas desde el escenario corpóreo de la vida, las labores del hogar se perciben como tareas pesadas y confusas, sometidas a los tirones de la necesidad y las exigencias de la naturaleza. Tareas carentes del brillo que da la luz pública y el reconocimiento de los demás. Hechos que nunca serán narrados ni elogiados, que no dejan rastro tras de sí ni tienen nada de heroicos. ${ }^{21}$ Esa visión marchita y opresiva del hogar

\footnotetext{
20 Chodorow explica que la forma en la que hemos sido maternizados influye en la forma en que seremos capaces de atender a un bebé. "[L]a actitud psicológica básica para lo parental se funda durante este período" (Chodorow, 1984, p. 93). Si la experiencia no fue buena, es posible que tratemos de enmendarlo al convertirnos en madres (Chodorow, 1984, p. 138).

21 Quizá no es extraño que sea una autora como Virginia Woolf quien haga esta reflexión sobre la importancia de las cosas concretas como los alimentos: "Es curiosa esa manera que tienen los novelistas de hacernos creer que las comidas son siempre memorables, por algo muy ingenioso que en ellas se dijo o algo muy sensato que se hizo. En cambio, rara vez dedican una palabra a los alimentos. Forma parte de la convención del novelista no mencionar
} 
se percibe, por ejemplo, cuando el joven Telémaco envía con soberbia a su madre al telar y la rueca, como señalamos más arriba. ${ }^{22}$ En esos hogares quedan recluidas fuerzas llenas de vida hasta volverlas oscuras y retorcidas. Las mujeres que viven en las trastiendas de la vida mientras sus maridos y sus hijos protagonizan gestas memorables no tiemblan cuando se tratan entre ellas: "Lengua silenciosa y rostro sereno mostraba a mi esposo. Sabía cuándo debía imponerme a él y cuándo, en cambio, dejarle la victoria". ${ }^{23}$

Sin embargo, la creatividad puede que tenga más que ver con esa labor cotidiana, lenta y cuidadosa, que con las grandes gestas heroicas, el acto creador que tanto irrita a Rodríguez Piedrabuena (2002, pp. 190-193), ese acto que como una llamarada omnipotente ofrece algo glorioso sin aparente esfuerzo o con un esfuerzo arrebatado. En el caso del bebé, no importa solo el día de su gestación ni el día de su nacimiento. Junto a ellos están todos los demás días (y noches) en los que el bebé debe ser cuidado, en cada momento como le corresponda, hasta valerse por sí mismo y separarse. Algo parecido a lo que supone escribir un libro o emprender la creación de una obra de arte.

En el día a día, hay que vivir la angustia de esperar a lograr las cosas, con esfuerzo, poco a poco, percibiendo los límites de nuestras

la sopa, el salmón o el pato, como si la sopa, el salmón y el pato carecieran por completo de importancia, como si nadie jamás fumara un cigarro o bebiera un vaso de vino" (Woolf, 2012b, p. 18). Es destacable, por otra parte, y en este mismo sentido, que toda la obra esté dedicada a la importancia de tener una habitación propia donde poder proteger y cultivar la letargia y la creatividad.

Si bien estoy asociando el cuidado de lo concreto a la feminidad, me gustaría advertir que feminidad y masculinidad, tal y como trato de aproximarme a ellas, no serían territorios separados, ni excluyentes, ni privativos de ningún género. A este respecto es valioso recordar que, para un pensador como Maimónides, el cuidado del cuerpo es esencial. Considera que no se puede atender al alma sin haber atendido antes al cuerpo (Roiz, 2013, pp. 128-129). El rechazo del cuerpo, sin embargo, está muy arraigado en la tradición grecolatina y cristiana. Sobre esta cuestión en relación con Boecio y con el gnosticismo, ver Dorado (2012a, 2013).

22 Palabras semejantes utiliza Héctor para hablarle a su esposa: "Pero yéndote a casa, cuida tus propios trabajos, la tela y la rueca, y a tus sirvientas ordénales ponerse al trabajo, y la guerra será al cuidado de los hombres todos que en Ilión han nacido, y a mí en especial" (Homero, 2008, VI, 490-493, p. 116).

23 Son palabras de Andrómaca a Hécuba (Eurípides, 1990b, p. 135). 
capacidades y nuestros medios, sin dejarse llevar por la ansiedad o la depresión. En esta situación, el contacto con la omnipotencia es constante y hay que aprender a protegerse de ella para que no signifique caer en la esterilidad. ${ }^{24}$

Esos son peligros muy serios que nos pueden hacer dimitir o abstenernos, tanto como las inhibiciones que nos implante el entorno. Inhibiciones que pueden llegar disimuladas con envoltorios cariñosos e inofensivos. No olvidemos que en ese entorno incluimos a las personas más cercanas y queridas. ${ }^{25}$

También implica prepararse para recibir algo bueno, y ser capaz de aceptarlo y disfrutarlo. Esa parte cotidiana y sostenida no se puede desvincular de la creatividad, que no significa otra cosa, en última instancia, que amor a la vida. ${ }^{26}$ "Es la percepción creativa [de la realidad

24 Según Piedrabuena, el creador "[m]antiene ánimo y motivación ante la fuerte carga emocional que supone el contraste entre lo que quiere conseguir y las limitadas destrezas que posee, para lo que necesita promocionar una aguda conciencia de sí; es por lo que no se permite distracciones ni dispersión en dinámicas institucionales regresivas" (Rodríguez Piedrabuena, 2002, p. 11). Esta es una idea sobre la que Piedrabuena insiste en varios momentos de su obra. Más adelante señala: "Estamos un poco a ciegas al escribir y mortificados por nuestras lagunas y limitaciones. Al encontrarse [el creador] con otros autores se organiza la crisis personal" (Rodríguez Piedrabuena, 2002, p. 24). El autor tiene que aceptar que el tema que estudia sobrepasa con mucho su capacidad como autor individual. Por ello, se da la fase depresiva que describe Melanie Klein (Rodríguez Piedrabuena, 2002, p. 23). El creador, sin embargo, es capaz de superar todos estos obstáculos que vienen de dentro y de fuera. "El fracaso no le asusta, sino que trata de hacer las cosas de otra manera, cambia la forma de pensar, la búsqueda de la verdad en ese campo determinado, y no oculta sus errores: es íntegro. Entusiasta y apasionado, pero se modera porque sabe que se equivoca, y mucho" (Rodríguez Piedrabuena, 2002, p. 11). Al plantearlo de este modo, sentimos que la intención del autor es benigna. Sus sentimientos parecen ser los de querer proteger a los creadores, honrar su labor e invitar a los lectores a atreverse a ser creativos. No obstante, la fortaleza y las cualidades que le atribuye son tantas que quizás a veces resulte un poco apabullante.

25 La creatividad implica una transformación de la persona y una vida en libertad. Los cambios que acontecen pueden separarnos de nuestro entorno y hacer saltar todos los dispositivos de alarma y control para contenerlos. A este respecto, ver la diferencia entre los ídolos y los objetos buenos; y los mecanismos de protección familiar que se pueden poner en marcha (Roiz, 2014, pp. 61 y ss.; 71 y ss.).

26 "Es preciso un gran amor, capaz de inspirar y de sostener ese esfuerzo continuo hacia la verdad, esa generosidad de conjunto y esa desnudez profunda que implica la génesis de 
externa] más que ninguna otra cosa la que hace al individuo sentir que merece la pena vivir la vida" (Winnicott, 1971, p. 65).

No obstante, también es fácil que lo cotidiano devenga rutinario y conservador. Cuando vemos a Penélope tejiendo de día y destejiendo de noche (la mortaja de su suegro, por cierto), percibimos que su protagonista está llevando a cabo una estrategia para no afrontar la realidad, ${ }^{27}$ en definitiva, para no pensar. ${ }^{28}$ Pura actividad mental. ${ }^{29}$

\section{La madre mágica}

En la relación que se establece entre la madre y el bebé, hay un gran desequilibrio. Ambos se involucran intensamente en la relación, pero el bebé depende de ella para sobrevivir. Como hemos mencionado anteriormente, la dependencia del bebé es absoluta. Además, él se experimenta confundido con su entorno, mientras que la madre o el materno, como adulto, es capaz de apreciar las identidades (Chodorow, 1984, p. 98). "Cuando decimos que el niño carece de identidad, lo que estamos diciendo — esto quizás sin saberlo claramente- es que el niño se halla inmerso en un mundo en donde nada tiene identidad para él, ya que él no puede entrar en el mundo de lo consciente,

toda obra de arte”. Henri Matisse (1869-1954), citado en Rodríguez Piedrabuena (2002, p. 80).

27 El motivo de que Penélope teja de día y desteja de noche su labor es ganar tiempo para espantar a los pretendientes que quieren casarse con ella y suplantar a Odiseo como su esposo y, sobre todo, como rey de Ítaca. Penélope les ha prometido que, cuando termine de tejer la mortaja de su suegro, elegirá a uno de ellos como su marido. El engaño dura tres años, hasta que es descubierta por las esclavas (Homero, 2011, II, 94-111, P. 61; XIX, 139157, P. 381).

28 Puede resultar paradójico que Arendt utilice la labor de Penélope como metáfora del pensamiento. Con ello Arendt quiere decir que el pensamiento sería una labor cotidiana que nunca se completa, que no ofrece resultados tangibles que puedan acumularse y que no puede abandonarse porque cada día debemos afrontar nuevas cuestiones sobre las que pensar (Arendt, 2002, p. 110). Aunque la metáfora es muy atractiva, la figura de Penélope nos ofrece muchos reparos. Su tarea, en realidad, es un truco pensado para engañar y retardar una decisión que no quiere o no sabe tomar. Por ello, la separaríamos del significado del pensamiento genuino que Arendt, por otra parte, desarrolla y protege con tanto cuidado. 29 Sobre el concepto de 'actividad mental' y su diferencia del 'pensamiento genuino', ver Roiz (1992, pp. 71 y ss.). 
caracterizado por un lenguaje que articula el pensamiento, las vivencias y los deseos en general" (Roiz, 1996, p. 162).

Aunque los maternos se hagan cargo del bebé con "devoción”, como diría Winnicott, tienen otros intereses además de su bebé. Se relacionan con otras personas, hacen otras actividades, incluso tendrán que atender su trabajo profesional. El hijo pronto sentirá que puede ser reemplazado, pero él no puede reemplazar a su madre o a la persona encargada de su cuidado (Chodorow, 1984, pp. 107-108).

Por otra parte, como ya indicamos, el bebé está viviendo literalmente su primera experiencia (Winnicott, 1987, p. 95). La madre, sin embargo, no. Ella ya ha sido un bebé y una niña y ahora es una mujer adulta. Es interesante notar que la experiencia como niña aflora en el momento de la maternidad. Gracias a haber vivido su relación con su madre, la nueva madre puede relacionarse con su bebé. Ella no lo recuerda, pero esa experiencia está presente en ella (Winnicott, 1987, p. 85). Este aspecto nos recuerda la importancia de considerar que en nuestro mundo interno no rige el principio de identidad aristotélico; en él no hay tiempo ni espacio en el sentido en el que consideramos el tiempo y el espacio en el mundo externo. Gracias a ello disponemos de un cauce riquísimo que nos permite relacionarnos con personas de edades y procedencias muy diferentes a la nuestra (Roiz, 2013, pp. 159-160).

Esta relación tan asimétrica funciona gracias a que la madre comprende la situación y se hace cargo de ella. La crianza del bebé depende de que la madre acepte atender todas las necesidades del bebé, a sabiendas de que está completamente desvalido y ni siquiera puede expresar sus deseos. Ella debe comunicarse con él sin palabras. Pero está disponible y dispuesta para hacer el esfuerzo. Mientras que la madre puede acercarse al mundo del bebé, el bebé no puede acercarse al mundo adulto de la madre, es incapaz (Winnicott, 1987, p. 95).

La madre logra cubrir las necesidades del bebé gracias a que se identifica con él. Él se encuentra en un estado de desvalimiento, pero hay alguien que ha aceptado atender su desvalimiento. El bebé lo vive 
como una experiencia omnipotente. Si está bien atendido, todos sus deseos son satisfechos. Él mismo — no distingue lo que es él y lo que no es él- es capaz de satisfacerlos. ${ }^{30}$ Cuando no lo son, sufre una angustia muy dolorosa. Podría decirse que el mundo del bebé es un mundo cargado de magia, "de explosiones y resortes" (Roiz, 1992, p. 37). Lo curioso es que de esta experiencia inicial nos guardaremos el recuerdo de la omnipotencia más que el del desvalimiento (Roiz, 1992, p. 94).

La labor de la madre anticipándose a las necesidades del bebé es muy valiosa en los primeros momentos en los que la dependencia es absoluta. Sin embargo, poco a poco la dependencia va disminuyendo. El niño adquiere la capacidad de hacer signos para mostrar sus necesidades. La madre debe ser capaz de adaptarse a esta nueva etapa y atender las necesidades del niño a medida que él se las expresa. Ya no puede interpretarle con esa empatía inicial y anticiparse. Aparece el riesgo de que actúe como una madre mágica y esto desagrade al niño. Si siente que se anticipa a sus necesidades, puede sentirse agobiado por ello (Chodorow, 1984, pp. 130-131; Winnicott, 1986, p. 247).

Si la madre hace demasiado bien su labor, porque tiene mucha experiencia, puede perjudicar al niño. Puede empezar a actuar perdiendo de vista al niño concreto que debe atender y a sus necesidades del momento. Se despega de la contingencia. Lo mismo puede ocurrirle a un psicoanalista experimentado. Es posible que empiece a sentirse incómodo con el tiempo que tardan sus pacientes en ir expresándose. Puede construir el diagnóstico mentalmente empleando experiencias previas. El problema será que ha dejado de ver a su paciente, de verle y de escucharle, y le está aplicando pensamientos que en realidad no le corresponden (Winnicott, 1986, pp. 247-248).

A este propósito es valioso considerar la importancia del pensamiento ampliado que introduce Arendt. Una prevención esencial es que, a

\footnotetext{
30 Este estado es denominado por Sigmund Freud "narcisismo primario". Cornelius Castoriadis (1922-1997) prefiere referirse a él como “autismo". Ver Dorado (2012a, pp. 115-117 y ss.).
} 
diferencia de la empatía, el pensamiento ampliado acepta la distancia entre las personas y no trata de suplantar al otro (Arendt, 1996, p. 254; Roiz, 2003, pp. 167-168). A pesar de ello se confía en la posibilidad de que se dé un entendimiento profundo entre ellas. Para lograrlo, se promueve una escucha receptiva que pueda servir para comprender al otro sin sustituirle por un montaje mental nuestro ${ }^{31}$ ni, en el otro extremo, someterle a nuestra vigilancia para conocerle a fondo. El pensamiento ampliado, así como la visión del asunto que tiene la retórica, puede significar una práctica muy democrática. Pero no hay que perder de vista que implica un acto muy generoso y muy confiado por ambas partes, y requiere un tiempo y una delicadeza que no siempre estamos dispuestos o capacitados para ofrecer.

\section{Entrada democrática a nuestras capacidades maternales}

En la creatividad está implícita la necesidad de aceptar la confusión y bajar los controles: "En los cerebros creadores sospecho que la razón ha retirado su vigilancia de las puertas de entrada, deja que las ideas se precipiten pêle y mêle al interior, y entonces es cuando advierte y examina el considerable montón que ha formado" (Rodríguez Piedrabuena, 2002, p. 11).

En la creación de la isegoría, este bajar los controles implicaría olvidarnos del brillo y la seguridad del "Me parece", "Yo pienso", "Yo creo". Es decir, tratar de diluir nuestro protagonismo y acercarnos al otro desde el mundo interno, con esa inteligencia silenciosa que nos hace capaces de transitar del mundo adulto al infantil y del mundo masculino al femenino en viajes de ida y vuelta que no acaban en conquistas de territorio ni en mapas cerrados. Esta es una tarea que quizá no es sencilla, y hay buenas razones para ello. En nuestras democracias, aún hay muchas resistencias a aceptar el relieve de los maternos, y con ellos del mundo infantil al que pertenecen, porque nos remiten

\footnotetext{
31 Es interesante el análisis de Chodorow sobre la "falsa empatía" con la que la madre se puede relacionar con su bebé (Chodorow, 1984, pp. 154-155).
} 
a un mundo de fuertes dependencias y de confusión, tareas difusas y falta de racionalidad (Roiz, 1996, pp. 155-157).

La maternidad nos demuestra la capacidad para traspasar nuestras identidades sin que eso signifique que las personas quedemos arruinadas, desposeídas de lo que somos o difuminadas en el anonimato. Una vía que se ha probado una y otra vez para lograr cercanía a pesar de nuestras diferencias son las identificaciones masivas con una bandera, una nación, un grupo, un clan ideológico o familiar. Pero quizá no sea necesario acudir a esa solución. En el cuidado de los maternos a su bebé, observamos cómo una persona se olvida de quién es para entender a otra y atenderla. La persona que lleva a cabo esa tarea, sin embargo, no deja de ser quién es por ello; al rato puede relacionarse con personas adultas y hacer actividades distintas. Los maternos son "individuos que se manejan constantemente en dos mundos reales" (Roiz, 1996, pp. 154-155).

Quizá podríamos pensar que la maternidad es un caso muy peculiar, algo excepcional que no se repetirá fuera de ese contexto. No lo creemos así. Esta relación especial y concreta, que todos hemos vivido sea de un lado, o de ambos, nos muestra con lupa de aumento nuestra extraordinaria capacidad para atender el desvalimiento y las partes infantiles de otras personas.

Si la dependencia quedara borrada de nuestras vidas después de estas primeras etapas, quizás estas reflexiones tendrían un alcance muy limitado. Quedarían restringidas al ámbito de la maternidad y la infancia. No tendría demasiado sentido plantearlas en relación con el gobierno de las personas adultas. Sin embargo, el hecho es que, aunque la dependencia absoluta solo dure un tiempo y poco a poco se vaya transformando en independencia, esta no llega a ser total (Winnicott, 1987, p. 90). Además, hay momentos de la vida en que se retrocede a esa situación de dependencia. ${ }^{32}$ Finalmente, en todo caso: "El vínculo madre-hijo [...] hace que todo hombre y toda mujer

32 Esto se observa, por ejemplo, cuando nos ponemos enfermos (Winnicott, 1987, p. 94). 
vivan hasta la muerte como hijo, ya que su vínculo maternal nunca se rompe ni se diluye" (Roiz, 1996, p. 161).

El desvalimiento y su contrapartida, que es la tentación de recurrir a la omnipotencia, van a acompañarnos de por vida.

\section{El techo de cristal}

En la atención a la dependencia del bebé, los maternos deben saber modular su grado de intervención con gran sabiduría. Deben estar muy atentos a las expresiones del hijo para estarpresente sin invadirle ni abandonarle. Algo que un maestro o una maestra democrática debe tener muy en cuenta. No puede lanzarle a la independencia antes de tiempo ni sujetarle a la dependencia más de lo debido. El cuidado maternal corre el peligro de caer en la "deprivación" o en la "sobreprotección"; también puede errar al aplicar sus atenciones desmesuradamente y a destiempo (Chodorow, 1984, pp. 130-131, 154).

Muchas preguntas nos asaltan de inmediato. ¿Qué es lo debido? ¿Cuándo es el momento oportuno para adoptar una actitud diferente? Con sabiduría, Winnicott explica que no hay un cronograma que se pueda seguir para atender al bebé de forma adecuada en cada momento. El proceso de paulatina adquisición de autonomía ni es lineal ni sigue un ritmo constante. En un momento, el niño requiere que le reconozcan mayor independencia y, al momento siguiente, lo contrario (Winnicott, 1986, p. 248). La madre debe ir acompasándose con él utilizando su buen juicio. No se trata solo de comprender las necesidades del niño. $\mathrm{Al}$ mismo tiempo tenemos que contar con que la madre puede desear mantener la dependencia más tiempo del debido, no por torpeza en interpretar la situación del niño, sino porque ella misma lo necesite, porque no sea capaz de superar esa etapa (Winnicott, 1986, p. 250). Que ella o él sea el personaje adulto no quiere decir que controle la situación.

En la Eneida, un pasaje del libro II nos habla de la importancia de las madres en cuidar el hogar, con todo lo que ello significa. Mientras los niños y las mujeres solteras reciben con alegría la entrada del caballo 
que les traerá la perdición, ${ }^{33}$ las madres —ellas que han sido creadoras de vida — se aferran a sostener los "jambas" de sus casas: "Allí las pávidas madres yerran por las casas ingentes y, abrazándolas, sostienen las jambas, y besos les clavan" (Virgilio, 2011, II, 489-490, p. 38).

En esta escena, se está produciendo una invasión que traerá la ruina de la ciudad. Nos conmueve la capacidad de las madres para percibir la destrucción que se avecina e intentar cuidar el "interior" de las casas (Virgilio, 2011, II, 486-488, p. 38).

Sin embargo, su coraje y su fortaleza pueden convertirse en algo monstruoso cuando pasa a ser una situación permanente. La omnipotencia maternal puede convertirse en un amuleto, un recurso mágico para resolver las desavenencias.

Al destapar lo que ocurre en el hogar, no se trata tanto, o solamente, de dar mayores poderes a las mujeres para equipararlas a los hombres en la vida pública. Esa es una faceta muy importante, pero estos avances pueden quedar sin un verdadero efecto transformador a menos que meditemos sobre cómo protegerlas de la omnipotencia que tienen en sus manos, ${ }^{34}$ una omnipotencia que genera odios y temores muy severos y duraderos de por vida. ${ }^{35}$

33 "Los niños en torno y las solteras muchachas cantan himnos, y gozan de tocar con la mano las cuerdas" (Virgilio, 2011, II, 238-239, p. 31).

34 Las palabras de Medea planeando el asesinato de sus hijos expresan con un dramatismo exacerbado lo que puede llegar a significar esta omnipotencia: "Seré yo misma, la que les di vida, la que les daré también muerte” (Eurípides, 1990a, p. 84). Otro ejemplo es el de Edipo, abandonado por sus padres, Layo y Yocasta, para evitar que se cumpliera un oráculo (Sófocles, 2011c, p. 230). Ana Iriarte destaca que el caso de Medea es particular y significativo porque hace uso de una prerrogativa, la de disponer de la vida de los hijos, que solo tenían los padres (Iriarte, 1996, pp. 84-90).

35 Una de las fantasías que despierta el temor a la fuerte dependencia de la madre es la de la posibilidad de procrear sin necesidad de mujeres. Así lo expresa Jasón: "Más valdría a los mortales engendrar hijos de otro modo y que no existiera la estirpe femenina. De ese modo los hombres no conocerían mal alguno" (Eurípides, 1990a, p. 65). Es muy revelador, como subraya Iriarte, que Atenea, "la diosa que protege y da nombre a la ciudad de Atenas", "la pólis democrática por excelencia", sea una diosa 'amátoros', es decir, 'sin madre'. Atenea "nace completamente armada de la cabeza de Zeus" (Iriarte, 1996, p. 73). Meditando sobre la obra de Simone de Beauvoir (1908-1986), Zerilli señala que "el útero es percibido como una 
La experiencia de omnipotencia puede trastocar a la madre e incapacitarla para dejar de serlo. En el ámbito de la creación intelectual $\mathrm{o}$ artística, la omnipotencia puede ser benigna y productiva, siempre y cuando se sea capaz de salir de ella. Normalmente, esto ocurrirá gracias a la intervención de otras personas. ${ }^{36}$ Para Arendt, no en vano, la pluralidad es una garantía protectora para no alimentar la fantasía de la soberanía (Arendt, 2005, pp. 226-227, 243, 255).

Refugiarse en la omnipotencia maternal puede desecar las otrora fértiles fuentes de la creatividad. Winnicott advierte que el tratamiento inadecuado de la omnipotencia del bebé por parte de la madre impedirá que aflore el verdadero self del bebé y hará que este bebé, de adulto, tenga que vivir emboscado en un falso self, incapacitado para afrontar la vida con creatividad (Winnicott, 1965, pp. 145-148, 152).

Una madre invasora que limita la autonomía y la creatividad del hijo o la hija también se convierte a sí misma en un ser aparentemente poderoso y principal, como una diosa, pero en realidad queda degradada a un ser parasitario de una vida ajena. Vivirá a través de los manejos de la vida de su hijo o de su hija, para lo cual debe resultarle imprescindible constantemente. La relación de Palas Atenea con Odiseo puede servirnos de ejemplo: "[E]l divino Odiseo despertó. Ya dormía él en su tierra patria, pero no la reconoció, después de tan larga ausencia. Había derramado niebla la diosa Palas Atenea, la hija de Zeus, para que él se sintiera perdido y ella se lo explicara todo" (Homero, 2011, XII, 187-191, p. 274).

Las madres relacionadas en solitario con la omnipotencia se exponen a grandes peligros mientras sienten que realizan su deber. Se pueden dedicar a tiempo completo a administrar la economía, los horarios, la alimentación y la educación de sus hijos, como gestoras eficaces de

tumba por aquél que se niega a reconocer el origen materno de su existencia: "Le gustaría haber aparecido en el mundo como Atenea, completamente desarrollado, completamente armado, invulnerable" (Zerilli, 1996, p. 176). El texto entrecomillado dentro de la cita pertenece a la obra The second sex de Simone de Beauvoir.

36 La propuesta de Chodorow es muy valiosa en este sentido. Vide supra nota 14. 
la vida. Unos talentos que puede que exporten a su lugar de trabajo y sean valoradas especialmente por ello (Percovich, 1996, pp. 239-240). Si tienen mucha iniciativa, controlarán las amistades, y hasta fijarán su profesión y sus relaciones amorosas. De este modo, lo que es un cuidado precioso y generoso que enciende la vida de una persona y la prepara para la luz pública se convertirá en una acción combustible que se consume en sí misma como la llama de una cerilla. Y como ella, en la soledad se quedará fría y chamuscada. Si el combustible es muy denso, también puede producir un incendio de inmolación que se vea desde el mar, como el que consume la vida de Dido ante la partida de Eneas (Virgilio, 2011, IV, 659-662, p. 89).

Detrás de todo ello puede que esté reptando un miedo muy desagradable a que el techo de cristal que nos cobija junto a nuestra madre se rompa, y al romperse nos produzca heridas o nos deje a la intemperie. Así lo canta el coro de mujeres corintias que acompañan y advierten a Medea:

¡Oh tierra paterna, oh casa, que nunca me vea sin patria, arrostrando la dura travesía de una vida en desamparo, el más miserable de los males!

¿Que la muerte, sí, la muerte me someta, antes de llegar a ese día!

Pues no hay dolor más alto que perder la tierra ancestral (Eurípides, 1990a, p. 68).

\section{Referencias}

Arendt, H. (1996). Verdad y política. En Entre elpasado y el futuro: ocho ejercicios de reflexión politica. Barcelona: Península.

Arendt, H. (2002). La vida del espiritu [1978]. Traducción de Fina Birulés y Carmen Corral. Barcelona: Paidós.

Arendt, H. (2005). La condición bumana [1958]. Introducción de Manuel Cruz, traducción de Manuel Gil Novales. Barcelona: Paidós. 
Arendt, H. (2006). ¿Qué es la politica? Introducción de Fina Birulés, traducción de Rosa Sala Carbó. Barcelona: Paidós ICE/UAB.

Biblia de Jerusalén. (2009). Bilbao: Desclée de Brouwer.

Chodorow, N. (1984). El ejercicio de la maternidad: psicoanálisis y sociología de la maternidad y la paternidad en la crianza de los hijos. Barcelona: Gedisa.

Dorado, J. (2012a). La mónada psíquica y la omnipotencia del ciudadano: Cornelius Castoriadis. Revista de Estudios Politicos, 157, 105-134.

Dorado, J. (2012b). El vuelo de Boecio. Ponencia presentada en el Seminario de Primavera, Grupo de Investigación de Retórica y Teoría Política, UCM.

Dorado, J. (2013). El laberinto gnóstico. Foro Interno, 13, 15-32.

Esquilo. (2005). Los siete contra Tebas. En J. Alsina Clota (Ed.), Tragedias completas (pp. 93-154). Madrid: Cátedra.

Eurípides. (1990a). Medea. En A. Melero Bellido (Ed.), Cuatro tragedias y un drama satírico (pp. 39-96). Madrid: Akal.

Eurípides. (1990b). Las troyanas. En A. Melero Bellido (Ed.), Cuatro tragedias y un drama satírico (pp. 97-158). Madrid: Akal.

Homero. (2008). Ilíada. Versión de Rubén Bonifaz Nuño. México: Universidad Nacional Autónoma de México.

Homero. (2011). Odisea. Versión de Carlos García Gual. Madrid: Alianza.

Iriarte, A. (1996). Ser madre en la cuna de la democracia o el valor de la paternidad. En S. Tubert (Ed.), Figuras de la madre (pp. 73-93). Madrid: Cátedra, Universitat de València, Instituto de la Mujer.

Kafka, F. (2005). El silencio de las sirenas: escritos y fragmentos póstumos. Traducción de Juan José del Solar, Joan Parra Contreras y Adan Kovacsics, prólogo de Jordi Llovet. Barcelona: Debolsillo.

Kantor, T. (2008). La clase muerta. Recuperado de http://youtu.be/ U0wdk3N53XY

Percovich, L. (1996). Posiciones amorales y relaciones éticas. En S. Tubert (Ed.), Figuras de la madre (pp. 225-258). Madrid: Cátedra, Universitat de València, Instituto de la Mujer.

Rodríguez Piedrabuena, J. A. (2002). La mente de los creadores. Un estudio de los procesos creativos desde la neurociencia y la psicología. Madrid: Biblioteca Nueva.

Roiz, J. (1992). El experimento moderno: politica y psicología al final del siglo XX. Madrid: Trotta.

Roiz, J. (1996). El gen democrático. Madrid: Trotta. 
Roiz, J. (2003). La recuperación del buen juicio: teoría politica en el siglo veinte. Madrid: Foro Interno.

Roiz, J. (2008). Sociedad vigilante y mundo judio en la concepción del Estado. Madrid: Editorial Complutense.

Roiz, J. (2013). El mundo interno y la política. Madrid: Plaza y Valdés.

Sófocles. (2011a). Ayax. En J. Vara Donado (Ed.), Tragedias completas (pp. 33-86). Madrid: Cátedra.

Sófocles. (2011b). Antígona. En J. Vara Donado (Ed.), Tragedias completas (pp. 139-194). Madrid: Cátedra.

Sófocles. (2011c). Edipo Rey. En J. Vara Donado (Ed.), Tragedias completas (pp. 195-264). Madrid: Cátedra.

Vegetti-Finzi, S. (1996). El mito de los orígenes. De la Madre a las madres, un camino de la identidad femenina. En S. Tubert (Ed.), Figuras de la madre (pp. 121-154). Madrid: Cátedra, Universitat de València, Instituto de la Mujer.

Virgilio. (2011). Eneida. Introducción, versión rítmica y notas de Rubén Bonifaz Nuño. México: Universidad Nacional Autónoma de México.

Winnicott, D. W. (1965). Ego distortion in terms of true and false self [1960]. En The Maturational Processes and the Facilitating Environment: Studies in the Theory of Emotional Development (pp. 140-152). New York: International UP Inc.

Winnicott, D. W. (1971). Creativity and its origins. En Playing and reality (pp. 65-85). London: Tavistock Publications.

Winnicott, D. W. (1986). The theory of the parent-infant relationship. En P. Buckley (Ed.), Essential Papers on Object Relations and the Development of the Child (pp. 233-253). New York \& London: New York University Press.

Winnicott, D. W. (1987). Babies and their Mothers. Edited by Clare Winnicott, Ray Shepherd and Madeleine Davis, introduction by Benjamin Spock. Reading, MA: Addison-Wesley.

Winnicott, D. W. (1990). Los bebés y sus madres. Compilado por Clare Winnicott, Ray Shepherd and Madeleine Davis, prólogo de Sir Peter Tizard. Barcelona, Buenos Aires, México: Paidós.

Wolin, S. S. (1986). Contract and Birthright. Political Theory, 14(2), 179-193. Recuperado de http://www.jstor.org/stable/191459

Woolf, V. (2012a). Las olas (1931). Traducción de Andrés Bosch. Barcelona: Lumen, Tusquets. 
Woolf, V. (2012b). Una habitación propia. Madrid: Alianza.

Woolf, V. (2014). Momentos del ser: sobre el movimiento del sol y la marea del océano. Foro Interno, 14, 193-211.

Zerilli, L. M. (1996). Un proceso sin sujeto: Simone de Beauvoir y Julia Kristeva, sobre la maternidad. En S. Tubert (Ed.), Figuras de la madre (pp. 155-188). Madrid: Cátedra, Universitat de València, Instituto de la Mujer. 